\title{
Update on the Management of Inflammatory Bowel Disease during Pregnancy and Breastfeeding
}

\author{
Sophie Restellini ${ }^{\mathrm{a}, \mathrm{b}} \quad$ Luc Biedermann $^{c}$ Petr Hruz ${ }^{\mathrm{d}}$ Christian Mottet $^{\mathrm{e}}$ \\ Annick Moens ${ }^{f}$ Marc Ferrante ${ }^{f}$ Alain M. Schoepfer ${ }^{g}$ on behalf of the Swiss \\ IBDnet, an official working group of the Swiss Society of Gastroenterology \\ ${ }^{a}$ Division of Gastroenterology and Hepatology, University Hospital of Geneva, Geneva, Switzerland; ${ }^{b}$ Division \\ of Gastroenterology, McGill University Health Center, Montreal, QC, Canada; ' Division of Gastroenterology and \\ Hepatology, University Hospital Zurich, Zurich, Switzerland; ' Division of Gastroenterology and Hepatology, \\ University Hospital Basel, Basel, Switzerland; ' $D$ Division of Gastroenterology and Hepatology, Cantonal Hospital Sion, \\ Sion, Switzerland; 'Division of Gastroenterology and Hepatology, University Hospital Leuven, Leuven, Belgium; \\ ${ }^{9}$ Centre Hospitalier Universitaire Vaudois and University of Lausanne, Lausanne, Switzerland
}

\section{Keywords}

Pregnancy $\cdot$ Inflammatory bowel disease $\cdot$ Breastfeeding

\begin{abstract}
Inflammatory bowel disease (IBD) affects patients during their peak reproductive years. This raises important questions, in both patients and healthcare providers, regarding conception, pregnancy, and breastfeeding. Lack of information and insufficient communication among healthcare providers can leave patients with limited information and even contradictory advice. Given the fact that pregnant and/or breastfeeding IBD patients are excluded from clinical studies the evidence on many questions related to pregnancy and postpartum period is limited. However, there exists increasing data from case series and cohort studies that allows to provide clinical guidance. The overarching concept is that optimizing the mother's health is critical for optimizing the health of the unborn child and benefit of continuing medical therapy in IBD during pregnancy outweighs possible risks in
\end{abstract}

most instances. This paper provides an up-to-date systematic review of the literature on IBD in pregnancy and proposes guidance to questions frequently encountered by healthcare professionals.

(c) 2020 S. Karger AG, Basel

\section{Introduction}

Inflammatory bowel disease (IBD) is represented by Crohn's disease (CD) and ulcerative colitis (UC). The peak age onset of these diseases coincides with childbearing years and approximately $25 \%$ of patients will have their first child after being diagnosed with IBD [1]. These diseases may therefore have an impact on fertility, pregnancy, and lactation.

Managing IBD during pregnancy can be challenging for healthcare providers since the health of both the mother and the fetus must be considered to take the optimal therapeutic decision. Control of disease activity is karger@karger.com

www.karger.com/dig

Karger ${ }^{\prime}=$
(C) 2020 S. Karger AG, Basel

(n)


crucial, especially at the time of conception, as uncontrolled disease is associated with higher risks of adverse pregnancy outcomes for both, the mother $[2,3]$ and the fetus [4-8].

Many concerns among IBD patients exist regarding the impact of the disease during pregnancy and the consequences on the child. A report suggested that $50 \%$ of women with IBD were worried about infertility, onefourth believed that it was more important to tolerate symptoms than to expose the fetus to their treatment, one-third believed that any medications given for IBD would be dangerous for their child, and three-fourths were concerned about transmitting the disease to their offspring [9-11]. These concerns can explain why certain women stop their treatment before conception or during pregnancy and lactation, despite the increasing evidence from recent studies confirming the benefit of continuing medical therapy in IBD during pregnancy [12-19].

Counseling patients during this emotional and important period of their lives is important. The management should be multidisciplinary including gastroenterologist and IBD nurse, obstetrician, primary care provider, pediatrician and if necessary surgeon. Communication between these care providers is crucial to avoid ambivalent or even contradictory counseling, which represents an extra source of anxiety for patients as well as potentially suboptimal adherence.

In 2015, The European Crohn's and Colitis Organisation published the second consensus on reproduction and pregnancy in IBD, which includes mainly data published until 2013 [20]. Important concepts have emerged recently from case-control and large cohort studies. This article seeks to incorporate up-to-date evidence relating to the management of IBD before conception, during pregnancy, and the postpartum period.

\section{Impact of IBD on Fertility}

Patients with IBD have fewer children compared to the general population, which is partly explained by the choice of some patients not to have children. Voluntary childlessness is reported in 17\% of women with IBD compared to $6 \%$ of women in the general population [21]. This choice results largely from fears that are often unjustified [22], reinforcing the importance of accurate counseling in this population to help them make their decision. A systematic review of 11 studies found no increased rate of infertility issues in women and men with IBD in remission and without a history of surgery [23]. However, the impact of IBD activity and certain treatments is important for both men and women regarding fertility and pregnancy outcomes.

\section{Women}

Medical therapy for IBD, including all biologic therapies, steroids, thiopurines, methotrexate, and mesalamine, does not decrease fertility [24-27]. However, women with active IBD may have decreased fertility [28-30] related to dyspareunia in patients with severe perianal or pelvic disease, fallopian tube occlusion secondary to pelvic adhesions, and ovarian dysfunction related to chronic illness or nutritional deficiencies [11]. Evidence suggests that patients having undergone proctocolectomy with ileal-pouch anal anastomosis (IPAA), proctectomy, and permanent ostomies are at increased risk for infertility. The decrease of fertility is mainly due to inflammation and scarring of the fallopian tubes [31-33]. Choosing a laparoscopic technique compared to laparotomy probably decreases infertility risk, and there is therefore no reason to avoid important surgery because a patient wants to be pregnant $[34,35]$. Inability to conceive for 6 months should lead to referral for infertility evaluation, especially if there is a history of open pelvic surgery [36]. IBD women who have undergone IPAA have a success rate for in vitro fertilization comparable to those without IBD or with IBD but without surgery [37].

\section{Men}

Less is known about the impact of disease activity and IBD specific medications on men's fertility and pregnancy outcome. A large internet-based voluntary cohort of IBD patients suggested that ensuring optimal control of disease is also important in male patients attempting to have children [38]. Men reported difficulties in conceiving more often when they had active or recently active disease. This association is probably explained by several factors such as decrease of desire for sexual activity related to anxiety and depression, effect of inflammation, and/or adverse effects of medications on semen characteristics. Several drugs may interfere with motility or sperm count. Sulfasalazine causes dose-related decrease in both sperm count and motility that is reversible. It should therefore be replaced by other 5-ASA formulations in men wishing to procreate [39]. Corticosteroids can cause a reversible decrease in sperm motility and concentration, but this observation does not seem to affect fertility in men $[25,40]$. Methotrexate (MTX) is contraindicated due to its teratogenicity and risk of oligospermia, which is reversible $4-5$ months after stopping the
28

Digestion 2020;101(suppl 1):27-42 DOI: $10.1159 / 000502886$
Restellini/Biedermann/Hruz/Mottet/ Moens/Ferrante/Schoepfer 
drug $[41,42]$. No evidence of effect on fertility outcomes is described for either thiopurine or antitumor necrosis factor (TNF) used by the father at the time of conception, although it has not been extensively examined [43-46]. Male patients suffering from UC who undergo IPAA may experience erectile dysfunction and retrograde ejaculation, also having surgery done at specialized center with laparoscopic approach help lowering the risks $[47,48]$.

\section{Effect of Pregnancy on the Course of IBD}

Risk of relapse during pregnancy in IBD women with stable disease is approximately $30 \%$, which is similar to nonpregnant patients $[7,49,50]$. Conversely, two-thirds of patients with active disease at conception will have persistent active disease during pregnancy [2,51]. Pregnancy also seems to lower the risk of long-term disease relapse $[52,53]$.

\section{Effect of IBD on pregnancy, Fetal, and Neonatal Outcomes}

Data on incidence of fetal abnormalities are conflicting, but reported risks are low $[10,51,54]$. Current evidence suggests that most of the time women who have quiescent disease before pregnancy have pregnancy outcomes similar to women without IBD. A 2-fold increased risk of low gestational weight compared with non-IBD patients has been reported in cohort studies [55]. Active disease is associated with higher rates of adverse outcomes such as fetal loss and stillbirth, preterm delivery, low birth weight, small for gestational age, thromboembolic events, cesarean section, increased neonatal intensive care admission, and low APGAR score [56, 57]. Adverse events result also on the degree of activity and its timing during pregnancy. It is difficult to determine whether disease activity itself or other confounding factors as discontinuation of treatments influence the increased risks. As such, it is recommended to control the disease prior to conception and to keep the mother in remission and well-nourished during pregnancy.

\section{Monitoring of Disease Activity during Pregnancy}

The diagnosis of active disease in pregnant IBD patients can be tricky as biological parameters such as Creactive protein (CRP), hemoglobin concentration, erythrocyte sedimentation rate, and serum albumin are affected by pregnancy [51]. To take appropriate decisions and obtain and maintain remission, its crucial to carefully monitor patients during the prenatal period.

\section{Endoscopy}

Recent data suggest that endoscopy is relatively safe during pregnancy. It is contraindicated only in obstetric complications such as placental abruption, ruptured membranes, or eclampsia. If endoscopy is necessary, the indication should be strong, and the procedure performed by experienced endoscopists to decrease the time of the procedure. Whenever possible, the procedure should be postponed after the first trimester because of the organogenesis. Pregnant women should be positioned in left lateral position or left pelvic tilt to avoid aortic and vena cava compression. An unsedated flexible sigmoidoscopy can be done in any trimester of pregnancy. Colonoscopy should be done with obstetric anesthesia monitoring. Benzodiazepines should be avoided, but propofol is considered safe during pregnancy, also it should preferably not be administered during the first trimester due to insufficient data. Fetal heartbeat should be detected before and after endoscopy and obstetric support should always be available.

\section{Imaging}

The safest methods of imaging during pregnancy remain ultrasound and magnetic resonance imaging. However, the view of abdominal contents with ultrasound can be limited especially in advanced gestation. When ultrasound results are inconclusive or for more complex cases magnetic resonance imaging without contrast can be proposed. In the absence of safety data, gadolinium is contraindicated during pregnancy. Abdominal X-ray and computed tomography should be avoided where possible because of concerns about side effects of irradiation on the fetus.

\section{Biomarkers of IBD Activity during Pregnancy and Therapeutic Drug Monitoring}

CRP and fecal calprotectin (FC) are helpful noninvasive markers used in IBD patients with relatively good correlation with disease activity. Also their accuracy and correlation with activity during pregnancy have not been well established [58-61], increasing body of evidence suggests, that FC may serve a reliable biomarker in all gestational periods and is less likely being prone to alterations as CRP.

A prospective evaluation of 30 pregnant women taking thiopurines found that maternal thiopurine metabolism changed during pregnancy, with 6-thioguanine concentration decreasing and 6-methylmercaptopurine concen- 
tration increasing as pregnancy progressed [62]. No maternal biochemical toxicities resulted from this shift, and thiopurine metabolism reverted to baseline after delivery. Few data are available on maternal serum levels in pregnancy. A small sample size study by Seow et al. [63] observed that infliximab (IFX) levels increased during pregnancy while adalimumab (ADA) levels remained stable. A recent prospective single-center cohort study suggested that ADA may be continued longer during pregnancy because transportation over the placenta is lower than for IFX [64]. Interestingly, a recent work including 12 patients on IFX and 4 patients on ADA with at least 2 intrapartum measurements suggested that maternal drug levels remain stable in patients on stable dosing of IFX or ADA in remission during pregnancy [65]. Further data are required to determine if and how pregnancy influences the pharmacokinetics of biologic treatments. Experts recommend in clinical practice to check maternal trough levels during the second trimester and adapt dosing appropriately during the third trimester in order to give the maximum interval possible before delivery [27].

\section{Drug Safety in Pregnancy}

Many women with IBD will stop their medication before or during pregnancy because of their concerns about drug safety, which may lead to increased risk of relapse and undesirable pregnancy outcome [66, 67].

Pregnant and breastfeeding women are typically excluded from clinical trials, and randomized controlled trials on safety data on medications are lacking. However, with multiple registry, cohort, and database sources, the safety of IBD medications (except for methotrexate) has been supported in the recent literature for conception, pregnancy, and lactation, even if the overall evidence is still poor and the strength for most of the recommendations still weak.

Recently, the US Food and Drug Administration has abandoned the product letter categories (A, B, C, D, and $\mathrm{X}$ ) and replaced them by detailed subsections (human, animal, and pharmacological) describing available information on potential risks and benefits for the mother, the fetus, and breastfed children [27] (Table 1).

\section{Antibiotics}

Metronidazole and ciprofloxacin are commonly prescribed in IBD patients. A meta-analysis of first-trimester quinolone exposure did not detect any particular increased risk [68]. Conversely, the use of metronidazole is controversial in pregnancy because 1 case-control study suggested a possible increased risk for oral clefts when used in the first trimester. However, 2 meta-analyses and 1 systematic review found no increased risk for congenital anomalies [69]. Amoxicillin-clavulanic acid is considered to be safe during pregnancy [70]. Rifaximin should be avoided in human pregnancy as no safety data have been published in human pregnancy and animal studies revealed evidence of teratogenicity. Several large trials are ongoing regarding the use of probiotics in pregnancies, and preliminary results reported improvement in certain outcomes including preterm birth, allergies, and infections in children [71].

\section{Aminosalicylates}

Aminosalicylates are commonly used to treat flares of mild to moderate UC and for maintenance of remission. Aminosalicylates, including sulfasalazine, are considered safe in pregnancy up to $3 \mathrm{~g} /$ day and should be continued in patients in whom remission has been obtained prior to conception $[72,73]$.

Sulfasalazine interferes with folate synthesis by inhibiting dihydrofolate reductase and pregnant women taking sulfasalazine should receive high-dose folic acid supplementation ( $2 \mathrm{mg}$ /day) to prevent neural tube defects [74].

Mesalamine derivatives can be continued during pregnancy with the exception of Asacol that contains in its coating dibutyl phthalate, which has been associated with congenital anomalies in animals at doses $>190$ times the therapeutic human dose [75]. Mesalamine enemas and suppositories may be continued without any risk.

\section{Corticosteroids}

Corticosteroids may be necessary during pregnancy to treat disease flares.

Older studies suggested that exposure to steroids during the first trimester may be associated to an increased risk of cleft lip and palate development [76]. This observation was not reported in a large Danish cohort of patients, who were exposed to any form of corticosteroids during the first trimester (OR 1.05; 95\% CI 0.80-1.38) [77]. In the Pregnancy in IBD and Neonatal Outcomes (PIANO) registry, the use of steroids was associated with an increased risk of certain maternofetal adverse events, such as preterm birth (OR 1.8; 95\% CI 1.0-3.1), low birth weight (OR 2.8; 95\% CI 1.3-6.1), and gestational diabetes (OR 2.8; 95\% CI 1.3-6.0) [78]. Therefore, patients on corticosteroids during pregnancy should receive blood pressure surveillance, glucose tolerance testing, and serial growth scans in the third trimester. Literature on the safe-
Restellini/Biedermann/Hruz/Mottet/ Moens/Ferrante/Schoepfer 
Table 1. IBD treatment during pregnancy (adapted from [27] and [114])

\begin{tabular}{|c|c|c|}
\hline Drug & Pregnancy safety & Comments \\
\hline \multicolumn{3}{|l|}{ Antibiotics } \\
\hline Amoxicillin with clavulanic acid & Low risk. Limited data & Preferred antibiotic during pregnancy \\
\hline Ciprofloxacin & Low risk. Animal data reported anomalies & Short courses for perianal disease \\
\hline Metronidazole & $\begin{array}{l}\text { Low risk. Avoid first trimester. Possible risk } \\
\text { of cleft lip }\end{array}$ & Short courses for perianal disease \\
\hline Rifaximin & Teratogenicity described in animal models & Avoid \\
\hline \multicolumn{3}{|l|}{ Aminosalicylates } \\
\hline Balsalazide & Low risk & Maintain prepregnancy dose \\
\hline Mesalamine & $\begin{array}{l}\text { Low risk. Exception: asacol contains dibutylphtalate } \\
\text { coating reported to be teratogenic in animal models }\end{array}$ & $\begin{array}{l}\text { Maintain prepregnancy dose. Switch Asacol to another mesalamine agent with equivalent } \\
\text { dose }\end{array}$ \\
\hline Sulfasalazine & Low risk & Maintain prepregnancy dose. Increase folic acid to $2 \mathrm{mg}$ daily \\
\hline \multicolumn{3}{|l|}{ Corticosteroids } \\
\hline Budesonide & Low risk & Short courses \\
\hline Prednisone & $\begin{array}{l}\text { Moderate risk. Mother: possible increase } \\
\text { risk of gestational diabetes, adrenal insufficiency, } \\
\text { premature rupture of membranes. Child: possible } \\
\text { increase risk of orofacial cleft (first-trimester } \\
\text { exposure), preterm birth, infections }\end{array}$ & Short courses. Use steroid-sparing agents when possible \\
\hline
\end{tabular}

\section{Immunomodulators}

Cyclosporine
Possible but limited data with reported increased Maintain prepregnancy dose risk of pregnancy complications, preterm birth, low birth weight

\begin{tabular}{|c|c|c|}
\hline Methotrexate & Contraindicated: teratogenic and abortifacient & Women must stop the drug 3-6 months before attempting conception \\
\hline $\begin{array}{l}\text { Thiopurines (azathioprine, } \\
\text { 6-mercaptopurine) }\end{array}$ & $\begin{array}{l}\text { Low risk in monotherapy Increased risk of infant } \\
\text { infections in combination therapy }\end{array}$ & $\begin{array}{l}\text { Maintain prepregnancy dose in monotherapy } \\
\text { If patient on combotherapy is in clinical and endoscopic remission with adequate trough } \\
\text { levels, consider stopping thiopurine and continuing biologic monotherapy } \\
\text { No introduction during pregnancy due to long delay of action and unpredictable risk of } \\
\text { developing medullary suppression or pancreatitis }\end{array}$ \\
\hline
\end{tabular}

\section{Small molecules}

Tofacitinib

Human data very limited

\section{Biologics}

Anti-TNF- $\alpha$

IFX
Low risk in monotherapy

\begin{tabular}{|c|c|c|c|}
\hline ADA & Low risk in monotherapy & $\begin{array}{l}\text { Maintain prepregnancy dosing. Continue } \\
\text { dosing until 3-4 week before delivery }\end{array}$ & $\begin{array}{l}\text { Maintain prepregnancy dosing. Stop around } \\
\text { week } 20-22 \text { in patient in remission }\end{array}$ \\
\hline GM & Low risk in monotherapy & $\begin{array}{l}\text { Maintain prepregnancy dosing. Continue } \\
\text { dosing until 4-6 week before delivery }\end{array}$ & $\begin{array}{l}\text { Maintain prepregnancy dosing. Stop around } \\
\text { week } 20-22 \text { in patient in remission }\end{array}$ \\
\hline $\mathrm{CZP}$ & Very low risk. Does not actively cross placenta & $\begin{array}{l}\text { Maintain prepregnancy dosing. Continue } \\
\text { scheduled dosing through pregnancy }\end{array}$ & $\begin{array}{l}\text { Maintain prepregnancy dosing. Continue } \\
\text { scheduled dosing through pregnancy }\end{array}$ \\
\hline \multicolumn{4}{|c|}{ Anti-integrin } \\
\hline VDZ & Low risk in monotherapy. Limited data & $\begin{array}{l}\text { Maintain prepregnancy dosing. Continue } \\
\text { dosing until 8-10 week before delivery }\end{array}$ & $\begin{array}{l}\text { Maintain prepregnancy dosing. Stop around } \\
\text { week } 20-22 \text { in patient in remission }\end{array}$ \\
\hline \multicolumn{4}{|c|}{ Anti-interleukins } \\
\hline UST & Low risk in monotherapy. Limited data & $\begin{array}{l}\text { Maintain prepregnancy dosing. Continue } \\
\text { dosing until } 8-10 \text { week before delivery }\end{array}$ & $\begin{array}{l}\text { Maintain prepregnancy dosing. Stop around } \\
\text { week } 20-22 \text { in patient in remission }\end{array}$ \\
\hline
\end{tabular}

IBD, inflammatory bowel disease; IFX, infliximab; ADA, adalimumab; GM, golimumab; CZP, certolizumab pegol; VDZ, vedolizumab; UST, ustekinumab. 
ty of using budesonide during pregnancy is more limited, but this drug appears to be a safe option for treatment of CD [79]. To our knowledge, there are no data available on the use of budesonide MMX or beclomethasone diproprionate during pregnancy.

In conclusion, the use of steroids is possible during pregnancy, and the benefit of disease control outweighs the risk of exposure. It is difficult to separate the effect of disease activity from a side effect of the drug as corticosteroids use reflects that disease is not in remission. Prolonged exposure should be avoided, and this drug should not be considered as a maintenance strategy treatment. Methylprednisolone and hydrocortisone should be the molecules of choice as their increased placental metabolism reduces the risk of fetal exposure compared to dexamethasone or betamethasone.

\section{Immunomodulators}

MTX is an antimetabolite that blocks the synthesis of thymidine. Exposure to MTX during organogenesis can lead to multiple malformations, mainly of limbs and skull known as methotrexate embryopathy. This drug is therefore contraindicated during conception and pregnancy. A woman of childbearing age on MTX should receive effective contraception. If accidentally conception occurs, therapeutic abortion should be discussed, but not necessarily performed [20]. In addition, after discontinuation of treatment, women should wait 3-6 months before attempting to become pregnant because of the long half-life of terminal elimination of the drug [80,81].

Thiopurines (azathioprine and 6-mercaptopurine) interfere with the synthesis of nucleic acid causing chromosome damage. These drugs have been reported to be teratogenic in animal studies at doses similar to those used in humans, but administration in these studies was intraperitoneal or parenteral, which significantly increased the bioavailability of the drug [82-86]. However, recent studies agreed on the safety of thiopurines both on the congenital malformation risk and fetal complications [87]. The strongest data supporting safety come from a multicenter retrospective study comparing disease activity and pregnancy outcomes of 187 patients treated with thiopurines, 66 patients treated with anti-TNF agents, and 318 unexposed IBD patients. In this study, no difference was found in pregnancy complications among the groups and multivariate analysis reported favorable global pregnancy outcomes, defined as a decreased rate of spontaneous abortion and lack of obstetric complications, associated with thiopurines intake [86]. In the PIANO registry, no increased risk of congenital anomalies or pregnancy complications was ob- served among $>335$ thiopurine-exposed pregnancies [88]. Literature is conflicting on the risk of infection in children aged 9-12 months exposed to thiopurine plus anti-TNF combination therapy. Some authors reported an increased risk of infection (relative risk 1.50; 95\% CI 1.08-2.09) [88], while others did not [89]. In conclusion, it is reasonable to continue thiopurine monotherapy during pregnancy to maintain remission, as the risks of active disease likely outweigh the risks associated with thiopurine use. Starting these treatments during pregnancy should be avoided because of the long delay of action and the unpredictable risk of developing medullary suppression or pancreatitis.

Calcineurin inhibitors act by suppressing the production of interleukins 2 and 3, inhibiting chemotaxis of neutrophils and inducing apoptosis in T cells. Data on calcineurin inhibitor in pregnancy are mainly extrapolated from transplant literature. A systematic review in IBD reported a possible link between their use and the occurrence of materno-fetal complications as hypertension, preeclampsia, gestational diabetes, preterm birth, low birth weight, and small-for-gestational-age neonates [51]. European Crohn's and Colitis Organisation guidelines discuss the use of cyclosporine as salvage therapy to avoid colectomy in pregnant patients with steroid-refractory fulminant UC flare [90], also this exceptional strategy should be reserved for expert centers. Compared with cyclosporine, tacrolimus has less risk of maternal hypertension but higher risk of neonatal hyperglycemia.

\section{Small Molecules}

Tofacitinib is an oral, small molecule Janus kinase inhibitor used for the treatment of rheumatoid arthritis, psoriatic arthritis, and UC. As a small molecule, tofacitinib is likely to cross the placental barrier and animal studies demonstrated teratogenicity. There are no controlled clinical studies designed to determine the effects of tofacitinib in pregnant women and prospectively collected registry data remain limited. Of 1,157 patients enrolled in the UC interventional studies, 301 were women of childbearing age. Eleven cases of maternal exposure and 14 cases of paternal exposure to tofacitinib (doses of 5 or $10 \mathrm{mg}$ twice daily) were identified. Outcomes included 15 healthy newborns with no fetal deaths, neonatal deaths, and congenital malformations reported. Two spontaneous abortions and 2 medical terminations were described. Outcomes across other tofacitinib studies and postmarketing cases were consistent, with a healthy newborn being the most common outcome and no fetal deaths [91]. However, given relatively few cases of pregnancy reported on this drug, conclusions cannot be drawn, and further studies are needed.
Restellini/Biedermann/Hruz/Mottet/ Moens/Ferrante/Schoepfer 


\section{Biologic Agents}

Biologic agents are IgG or fragments that are to a various extent actively transported across the placenta by the neonatal $\mathrm{Fc}$ receptor, which becomes functional at week 13 of gestation [92]. Eighty percentage of transfer occurs during the third trimester and fetal IgG concentrations are increased logarithmically from gestational week 20 to delivery [93-95]. As a consequence of this active transport across the placenta, cord blood biologics concentrations can exceed maternal levels by up to 4 -fold at birth and may be detectable in children for up to 12 months [66], raising concern about possible adverse effects on the development of the immune system of the infant [96]. Organogenesis occurs before transplacental anti-TNF drug transfer and to date no association was observed between congenital malformations and biologic agents.

\section{Anti-TNF Agents}

The 4 anti-TNFs approved in IBD are IFX, ADA, certolizumab pegol (CZP), and golimumab. CZP differs from the others in that it is a pegylated Fab fragment anti-TNF agent. This results in clinically insignificant drug levels in infants. Series on $>100$ IBD patients exposed during pregnancy to IFX [97], ADA [98], and CZP [99] found no adverse effect on pregnancy outcomes. Golimumab is supposed to have a similar safety profile. To date, no evidence was found for an association between treatment with TNF- $\alpha$ inhibitors for IBD in pregnancy and risk of congenital anomalies compared with diseasematched pregnancies. More than 500 women in the ongoing PIANO registry have been exposed to the aforementioned anti-TNF medications during pregnancy, and no increased risk with adverse pregnancy outcomes was observed [88]. A systematic review by Nielsen et al. [94] was consistent with these finding with no miscarriages, preterm deliveries, stillbirth, low birth weight, congenital malformations, and/or infections noted even when the drug was administered during the third trimester. A recent meta-analysis of 5 studies with 1,216 IBD patients neither found an increase in adverse outcomes in women taking anti-TNF therapy compared with unexposed controls (OR 1.00; 95\% CI 0.72-1.41), including preterm delivery (OR 1.00; 95\% CI 0.62-1.62), low birth weight (OR 1.05 ; 95\% CI 0.62-1.78), and congenital anomalies (OR 1.10 ; 95\% CI 0.58-2.09) [100]. However, women receiving an anti-TNF in combination with thiopurine had higher risk of preterm delivery (OR 2.4; 95\% CI 1.3-4.3) and pregnancy complication (OR 1.7; 95\% CI 1.0-2.2) compared with unexposed women [100]. These observa- tions reflect also probably that these patients had a more active disease. In addition, a risk of delayed infant infections was reported.

\section{Anti-integrin Agents}

Vedolizumab (VDZ) is a gut-selective humanized IgG-1 monoclonal antibody to $\alpha 4 \beta 7$ integrin approved for both CD and UC. A reproductive study of VDZ in pregnant primates demonstrated no evidence of adverse effects on development after intravenous administration of VDZ at doses 20 times the equivalent of those recommended for humans [101]. To date, we have limited data available on human pregnancy safety. A recent case series described the evolution of $24 \mathrm{VDZ}$ treated pregnancies. No new safety concerns for pregnancy outcomes in females directly or indirectly exposed to VDZ were observed [102]. An international retrospective study reported pregnancy and neonatal complication in 24 women treated with VDZ with 12 live births, 4 spontaneous abortions, and 5 elective abortions [103]. More recently, the same group conduced a retrospective European study where gastroenterologists were asked to report all VDZ exposed pregnancies as well as neonatal outcomes through an electronic case report form. There was no difference in miscarriage rates between the VDZ exposed group and a control group of patients exposed to antiTNF (16 vs. $13 \%, p=0.71$ ) or a control group of patients neither exposed to immunosuppressors nor to biologics (16 vs. $10 \%, p=0.236$ ). After exclusion of patients with active disease, the number of miscarriages was similar between VDZ group and patients in other groups [104]. Therefore, active disease in pregnancy rather than drug effect seems to have been the driver of this adverse pregnancy outcome. Experts suggest to use VDZ for women of childbearing age if indicated. Still, if the childbearing age woman is bionaive, most data are available with antiTNF agents, and therefore maybe anti-TNF, and especially CZP are most appropriate as first-line treatment option.

Anti-Interleukin IL-12-23

Ustekinumab is an IgG1 monoclonal anti-interleukin 12-23 antibody approved for psoriasis, psoriatic arthritis, and more recently for CD. A series of 26 exposed pregnancies reported 5 spontaneous abortions (19\%), a rate that is similar to the general population [105]. A cohort of 226 women treated with Ustekinumab for psoriasis or $\mathrm{CD}$ will be presented this year and no specific signal is reported to date compared to the general population [106]. 


\section{To Stop or Not to Stop Treatment during Pregnancy: Is the Debate Over?}

The strategy regarding the discontinuation of antiTNF therapy early during pregnancy poses several problems. Stopping treatment is associated with a higher risk of a flare during pregnancy and during the postpartum period and increase in the risk of developing antibodies due to lower trough levels leading possibly to loss of response to the drug after resuming treatment.

Discontinuation of anti-TNF- $\alpha$ during pregnancy may be considered under certain circumstances in patients who are at very low risk of relapse with an objective sustained endoscopic remission since $<6$ months before conception, no previous loss of response to anti-TNFs or need for dose optimization, appropriate therapeutic levels before conception, no hospitalization in the last 3 years, and no prior bowel resection [107].

As mentioned previously, there is no evidence that continuing anti-TNF therapy during pregnancy has a negative impact on the pregnancy or children's outcomes $[108,109]$. In patients with active disease during the second trimester, the benefit of continuing anti-TNF therapy during the third trimester outweighs the potential risk $[26,88,89]$. To minimize transplacental transfer near the time of delivery, biologic dosing can be adjusted to achieve trough or lowest serum drug concentrations at the estimated date. Although this strategy is probably safe, we do not have solid data to confirm it, and this is why most experts agree to stop biological therapies around week 20 in patients in remission (Table 1) [26].

\section{Delivery Mode}

Women with IBD have twice as many cesarean deliveries as women in the general population [31]. Most of the time, a caesarean section is proposed or requested because of unjustified fears on the part of patients or care providers. Also there is no contraindication to vaginal delivery in the majority of cases [110], a healthy IBD patient should be able to have a successful vaginal delivery. Episiotomy should be avoided whenever possible as it can trigger perianal disease. Women with active perianal or rectal disease involvement and open rectovaginal fistula at the time of delivery should however have planned cesarean section [111]. In this population caesarean delivery should be performed by a senior obstetrician in order to decrease the risk of intraoperative organ injury. IPAA is a relative contraindication for vaginal delivery.

\section{Postpartum Period and Lactation}

\section{Postpartum}

The risk of disease relapse is higher in the postpartum period. This risk is mainly a consequence of discontinuation of IBD therapies during pregnancy with extended period of time before resuming treatment during the postpartum period [112]. In the pregnant IBD population from the French GETAID cohort, 14\% of women who discontinued anti-TNF treatment before week 30 of gestation while in remission experienced a relapse during the last trimester of pregnancy with a complicated disease course in $75 \%$ of cases ( 8 cases of prematurity and 1 case of colectomy for severe acute colitis) and a third of them had a flare during the early post-partum period before week 3 . The relapse rate was $26 \%$ in the early postpartum period among women who continued anti-TNF therapy throughout pregnancy because of active disease [113]. In the absence of infectious complications, biological treatment could be resumed $24 \mathrm{~h}$ after vaginal delivery and $48 \mathrm{~h}$ after cesarean delivery [27]. For weight-based dosing treatments, it is usually recommended to consider the mother's weight before pregnancy. The dose will then be adjusted according to several factors including disease activity, possible persistent weight gain postpartum and serum concentrations. Other IBD treatments can be continued in the postpartum period. MTX can be restarted postpartum if the mother is not lactating [114].

After a cesarean delivery, patients are at higher risk of developing an ileus, especially patients with IPAA in whom the pouch was manipulated during the delivery. Supportive measures and early feeding may decrease this risk [115]. Patients with an ostomy are more at risk of stoma complications during pregnancy and after delivery. It is recommended to avoid excessive weight gain during pregnancy and seek for advice to colorectal surgeon and a specialist nurse [114]. In case of cesarean section, simply covering the ostomy with gauze is sufficient to protect the operative field [116].

\section{Lactation}

A significant number of women with IBD do not breastfeed their children despite the fact that benefits of breastfeeding have been demonstrated to be substantial to both mother and child [117].

The relationship between breastfeeding and disease activity usually reflects the consequence of IBD therapies discontinuation, as $60 \%$ of women discontinued
Restellini/Biedermann/Hruz/Mottet/ Moens/Ferrante/Schoepfer 
Table 2. IBD treatment and breastfeeding (adapted from [27] and [114])

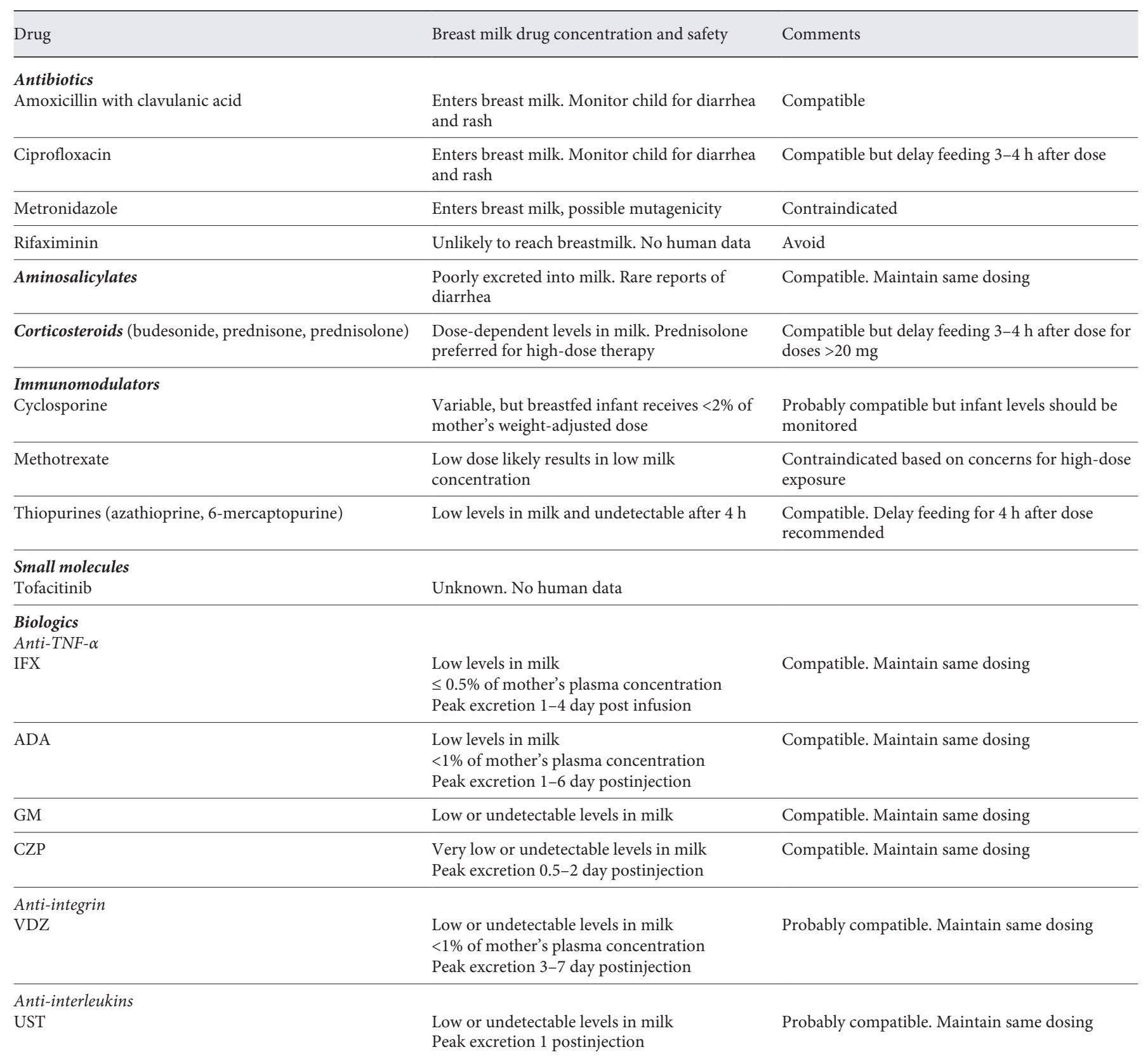

IBD, inflammatory bowel disease; IFX, infliximab; ADA, adalimumab; GM, golimumab; CZP, certolizumab pegol; VDZ, vedolizumab; UST, ustekinumab.

their medications in the postpartum period for fear of medication transmission in breast milk $[66,111]$. In the PIANO registry, the breastfeeding rate was significantly lower in women on immunomodulators and biologic treatments [118]. Although, literature is sparse in this field and long-term safety data are missing, the vast ma- jority of medications prescribed for IBD are either undetectable in breast milk or present in concentrations that would not be expected to harm the breastfeeding infant (Table 2) [114]. Clinicians can rely on LactMed, which is a free online database sponsored by the US National Library of Medicine, that provides reliable infor- 
mation on drugs and lactation. Treatments derived from mesalamine are generally found in the milk but are well tolerated. Only isolated cases of diarrhea were reported in exposed children. 5-ASA agents (mesalamine, balsalazide, and olsalazine) can therefore be continued during lactation. Those formulations are preferred to sulfasalazine due to the unknown side effects of drug metabolite, which are excreted into milk at concentrations that are higher than in the mother and known for hemolytic and antimicrobial properties. Corticosteroids low dose and thiopurines are detected in small amounts in the milk [119]. Some data suggest that higher dose of prednisone ( $>20 \mathrm{mg} /$ day) can result in higher levels in the breastfed infant and cause temporary loss of milk supply. Thiopurines are not detected in breast milk $4 \mathrm{~h}$ from dosing. Although it is not absolutely necessary, some experts recommend avoiding breastfeeding 3-4 $\mathrm{h}$ after taking these medications in order to limit the amount of drug transmitted onto the child. In most studies, the concentrations of biological agents found in milk are minimal $(<1 \%$ of serum concentration) as the drug is degraded in the stomach of the child and no harm from breastfeeding on biologic therapies has been described [120]. Data for anti-interleukin 12-23 and anti-integrin are very limited but due to limited transfer detectable and their monoclonal antibody molecular structures it is presumed that they are compatible with lactation $[121,122]$. Women on tofacitinib are advised not to breastfeed due to the lack of data on this molecule during the lactation period. The recommended duration of breastfeeding is the same as for women without IBD. Exclusive breastfeeding for 6 months, with continuation of breastfeeding for 1 year or longer as mutually desired by mother and infant is recommended for all mothers by the American Academy of Pediatrics.

\section{Approach to the Pregnant Woman with IBD}

It is now well established that preconception counseling associated to a multidisciplinary approach involving all providers, leading to better outcomes and less anxiety among IBD patients. When different healthcare providers and/or family provide contradictory advice, patients are most likely to experience anxiety. Preconception counseling has been associated with increased compliance with medications, disease control, and improved outcomes [29].

\section{Preconception Counseling}

IBD patients in childbearing age should always be asked if they have a pregnancy plan in the near future. In this way, the gastroenterologist will be able to take the time to reassure the patient about the safety of most treatments used during pregnancy and lactation. He will also have the opportunity to reassess disease activity and achieve remission before attempting conception. Laboratory analysis, dosage of FC, and endoscopy prior to conception, if endoscopic remission has not been assessed before, should be part of the workup. This is also a good moment to ensure that basic care has been provided such as screening for anemia and vitamin deficiency, vaccinations update, supplementation for folic acid, and smoking cessation. At this point, Asacol should be replaced by another Mesalamine formulation (Fig. 1).

\section{Management during Pregnancy}

The risk of adverse outcomes is increased in woman with IBD during the pregnancy, even if their disease is in endoscopic remission [123]. Therefore, close monitoring is recommended during pregnancy in this high-risk population.

In each trimester, FC and serum inflammatory markers, as well as gestational weight gain, should be monitored for evidence of disease activity and poor nutrition. If available, a trough level of biologic agent can be checked in the late second trimester to determine timing and dose of biologic agent in the third trimester. In the third trimester as well as in the postpartum, the pediatrician should be informed that live vaccines are contraindicated in infant exposed to biologic treatments. The management of flares would be similar to the nonpregnant patient with the exception that traditional serum markers of disease activity, such as sedimentation rate, hemoglobin, and albumin, are abnormal in pregnancy (Fig. 2).

\section{Impact of IBD for the Baby}

\section{$I B D$ and Heredity}

Genetic risk of CD is higher than for UC in European cohort studies. Having multiple family members with IBD increases the risk for children with IBD. In monozygotic twins studies, $20-56 \%$ of CD and 6-19\% of UC had concordance [124]. With maternal $\mathrm{CD}$, incidence rate ratio for $\mathrm{CD}$ is 6.3 in offspring, and the absolute risk of an offspring developing CD is $2.7 \%$. With maternal UC,
36

Digestion 2020;101(suppl 1):27-42 DOI: $10.1159 / 000502886$
Restellini/Biedermann/Hruz/Mottet/ Moens/Ferrante/Schoepfer 


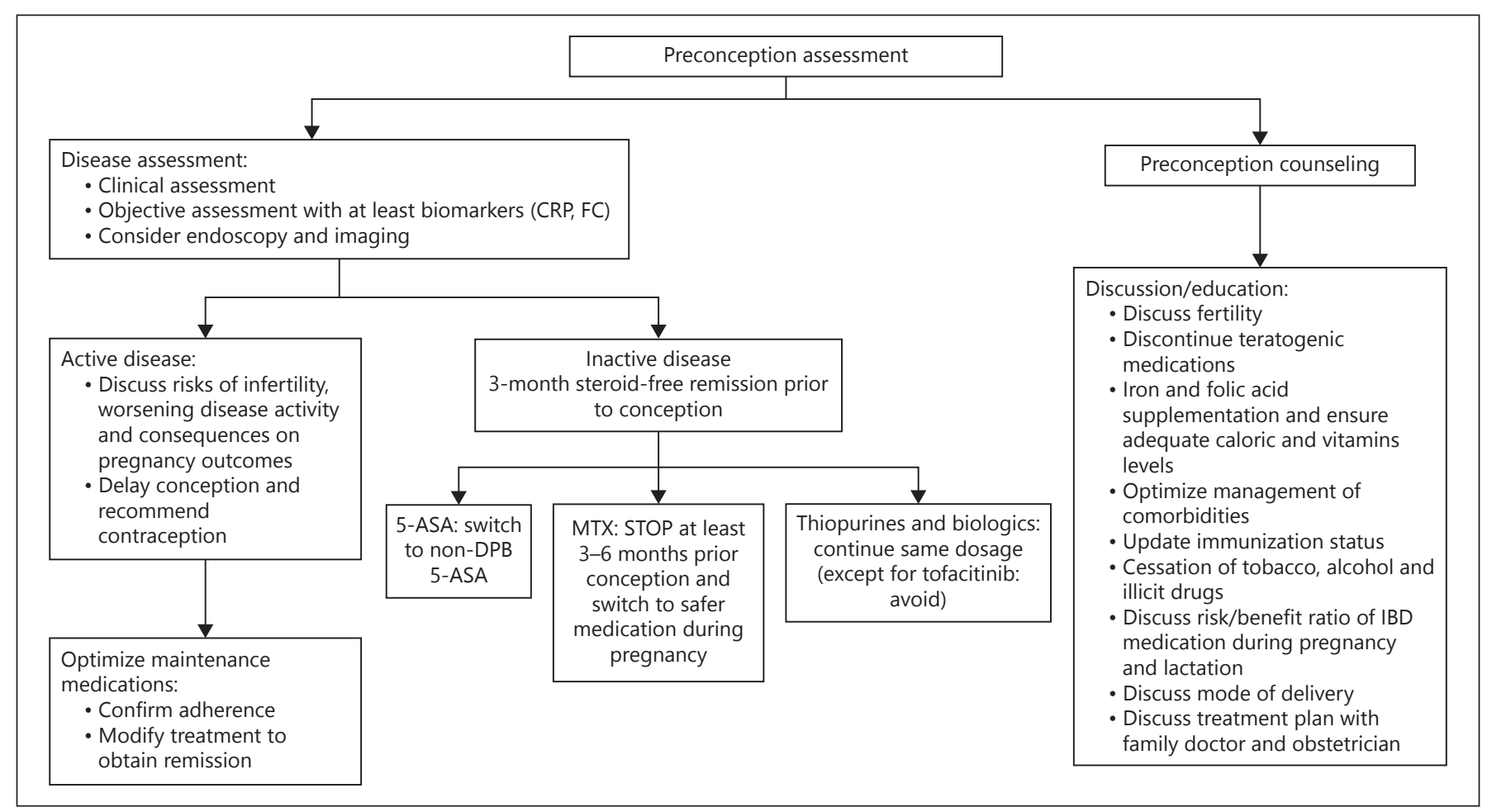

Fig. 1. Algorithm of care during preconception period (adapted from [114]). CRP, C-reactive protein; FC, fecal calprotectin; MTX, methotrexate; 5-ASA, 5-amino-salacylic acid; DPB, dibutyl phthalate; IBD, inflammatory bowel disease.

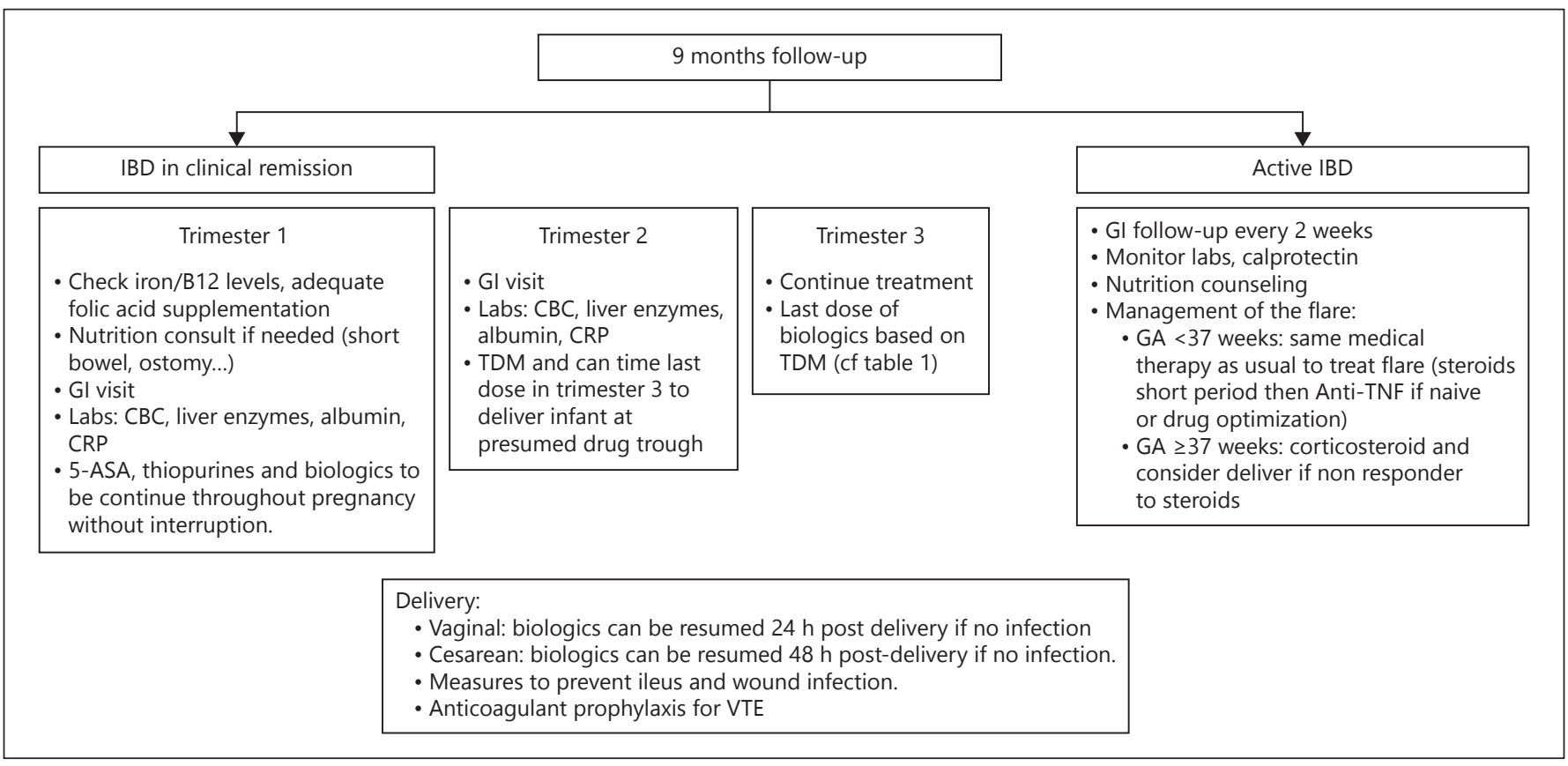

Fig. 2. Algorithm of care during pregnancy (adapted from [114]). IBD, inflammatory bowel disease; CRP, Creactive protein; GI, gastroenterologist; $\mathrm{CBC}$, complete blood count; TDM, therapeutic drug monitoring; GA, gestational age; VTE, venous thromboembolism; 5-ASA, 5-amino-salacylic acid. 
this incidence rate ratio is 3.7 for $\mathrm{UC}$ in an offspring, and the absolute risk of an offspring developing UC is $1.6 \%$ [125]. When both parents have the disease the risk of developing IBD rises to $30 \%$ [114]. Currently, no genetic test is available to predict whether the child will develop IBD.

\section{Infection and Vaccination}

Parents and pediatricians should be vigilant about infections, especially if the child was exposed to combination of thiopurines and biologics. A systematic review of anti-TNF use during IBD pregnancies found no increased risk of infections in the first year of infant life [94]. However, individual cases of serious infection have been reported [47]. In the PIANO registry, there is 1 case of vertical histoplasmosis transfer involving a mother taking IFX $10 \mathrm{mg} / \mathrm{kg}$ every 6 weeks who had supratherapeutic IFX levels at birth. It is recommended to minimize unnecessary antibiotic exposure, as that may increase the risk of developing CD later in childhood. Clinically significant levels can be found in newborn infants for up to 6 months after birth. Avoidance of live vaccines in infants exposed to biologic therapy during the third trimester of pregnancy is recommended until at least after 6 months because significant levels can be found in infants up to 6 months after birth and may lead to clinically relevant neonatal immunosuppression. The rotavirus vaccine postdelivery is the only live vaccine administered before 6 months in certain country such as in the United States. The first dose should be administered before 15 weeks of age to be more effective.

\section{Mental Development}

No evidence suggests that babies born to mothers with IBD regardless of medication exposure have any developmental delays. Data on developmental milestones from the PIANO registry support the lack of negative impact of IBD treatments on development. Moreover, infants with higher anti-TNF drug levels at birth had statistically superior achievement of developmental milestones compared with infants with lower birth drug levels. The hypothesis of effects of inflammation in utero on the developing brain has been reported and pro-inflammatory mediators negatively influence both hippocampal neurogenesis and neuronal cytoarchitecture during brain development. The importance of good inflammatory control during pregnancy should therefore be emphasized when counseling women with IBD [126].

\section{Conclusions}

IBD affects patients during their peak reproductive years raising important questions, in both patients and healthcare providers, regarding conception, pregnancy, and breastfeeding. Lack of information and poor communication among healthcare providers can leave patients with limited information and contradictory advice. Although there are clear limitations to the evidence base in this area, expert groups have nonetheless provided clear guidance on how best to answer these questions. Gastroenterologists are a key resource to provide reassurance and guidance during this important period of patients' lives, and they should work with other healthcare providers. The overarching concept is that optimizing the mother's health is critical for optimizing the health of the child and benefit of continuing medical therapy in IBD during pregnancy outweighs possible risks in most instances.

\section{Acknowledgment}

None.

\section{Disclosure Statement}

S.R., L.B., P.H., C.M., and A.M. have no conflicts of interest to declare. M.F.: research grant: Janssen, Pfizer, Takeda. Consultancy: Abbvie, Boehringer-Ingelheim, Ferring, Janssen, Mitsubishi Tanabe, Takeda, MSD, Pfizer. Speaker's fee: Abbvie, BoehringerIngelheim, Chiesi, Ferring, Janssen, Lamepro, Mitsubishi Tanabe, MSD, Pfizer, Takeda, Tramedico, Tillotts, Zeria. A.M.S.: consultancy for Abbvie, Janssen, MSD, Takeda, Pfizer. Speaker fees: Abbvie, MSD, Takeda, MSD.

\section{Funding Sources}

There is no funding to declare.

\section{Author Contributions}

S.R. and A.M.S.: conception and design. S.R. and A.M.S.: drafting of the article. S.R., L.B., P.H., C.M., A.M., M.F., and A.M.S.: critical revision of the article for important intellectual content. S.R., L.B., P.H., C.M., A.M., M.F., and A.M.S.: final approval of the article.
Restellini/Biedermann/Hruz/Mottet/ Moens/Ferrante/Schoepfer 


\section{References}

1 Ng SC, Shi HY, Hamidi N, Underwood FE, Tang W, Benchimol EI, et al. Worldwide incidence and prevalence of inflammatory bowel disease in the 21st century: a systematic review of population-based studies. Lancet. 2018 Dec;390(10114):2769-78.

2 Abhyankar A, Ham M, Moss AC. Meta-analysis: the impact of disease activity at conception on disease activity during pregnancy in patients with inflammatory bowel disease. Aliment Pharmacol Ther. 2013 Sep;38(5): 460-6.

3 Pedersen N, Bortoli A, Duricova D, D Inca R, Panelli MR, Gisbert JP, et al.; European Crohn-Colitis Organisation-ECCO-Study Group of Epidemiology Committee-EpiCom. The course of inflammatory bowel disease during pregnancy and postpartum: a prospective European ECCO-EpiCom Study of 209 pregnant women. Aliment Pharmacol Ther. 2013 Sep;38(5):501-12.

4 Cornish J, Tan E, Teare J, Teoh TG, Rai R, Clark SK, et al. A meta-analysis on the influence of inflammatory bowel disease on pregnancy. Gut. 2007 Jun;56(6):830-7.

5 Bröms G, Granath F, Linder M, Stephansson $\mathrm{O}$, Elmberg M, Kieler H. Birth outcomes in women with inflammatory bowel disease: effects of disease activity and drug exposure. Inflamm Bowel Dis. 2014 Jun;20(6):1091-8.

6 Ujihara M, Ando T, Ishiguro K, Maeda O, Watanabe O, Hirayama Y, et al. Importance of appropriate pharmaceutical management in pregnant women with ulcerative colitis. BMC Res Notes. 2013 May;6(1):210.

7 Reddy D, Murphy SJ, Kane SV, Present DH, Kornbluth AA. Relapses of inflammatory bowel disease during pregnancy: in-hospital management and birth outcomes. Am J Gastroenterol. 2008 May;103(5):1203-9.

8 Stephansson O, Larsson H, Pedersen L, Kieler H, Granath F, Ludvigsson JF, et al. Congenital abnormalities and other birth outcomes in children born to women with ulcerative colitis in Denmark and Sweden. Inflamm Bowel Dis. 2011 Mar; 17(3):795-801.

9 Selinger CP, Eaden J, Selby W, Jones DB, Katelaris P, Chapman G, et al. Inflammatory bowel disease and pregnancy: lack of knowledge is associated with negative views. J Crohn's Colitis. 2013 Jul;7(6):e206-13.

10 Vermeire S, Carbonnel F, Coulie PG, Geenen V, Hazes JM, Masson PL, et al. Management of inflammatory bowel disease in pregnancy. J Crohn's Colitis. 2012 Sep;6(8):811-23.

11 Huang VW, Habal FM. From conception to delivery: managing the pregnant inflammatory bowel disease patient. World J Gastroenterol. 2014 Apr;20(13):3495-506.

12 Van Assche G, Dignass A, Reinisch W, van der Woude CJ, Sturm A, De Vos M, et al.; European Crohn's and Colitis Organisation (ECCO). The second European evidencebased Consensus on the diagnosis and management of Crohn's disease: special situa- tions. J Crohn's Colitis. 2010 Feb;4(1):63101.

13 Biancone L, Michetti P, Travis S, Escher JC, Moser G, Forbes A, et al.; European Crohn's and Colitis Organisation (ECCO). European evidence-based Consensus on the management of ulcerative colitis: special situations. J Crohn's Colitis. 2008 Mar;2(1):63-92.

14 Beaulieu DB, Kane S. Inflammatory bowel disease in pregnancy. World J Gastroenterol. 2011 Jun;17(22):2696-701.

15 Dubinsky M, Abraham B, Mahadevan U. Management of the pregnant IBD patient. Inflamm Bowel Dis. 2008 Dec;14(12):1736-50.

16 Habal FM, Huang VW. Review article: a decision-making algorithm for the management of pregnancy in the inflammatory bowel disease patient. Aliment Pharmacol Ther. 2012 Mar;35(5):501-15.

17 Habal FM, Ravindran NC. Management of inflammatory bowel disease in the pregnant patient. World J Gastroenterol. 2008 Mar; 14(9):1326-32.

18 Mottet C, Juillerat P, Pittet V, Gonvers JJ, Froehlich F, Vader JP, et al. Pregnancy and breastfeeding in patients with Crohn's disease. Digestion. 2007;76(2):149-60.

19 Bortoli A, Pedersen N, Duricova D, D'Inca R, Gionchetti P, Panelli MR, et al.; European Crohn-Colitis Organisation (ECCO) Study Group of Epidemiologic Committee (EpiCom). Pregnancy outcome in inflammatory bowel disease: prospective European casecontrol ECCO-EpiCom study, 2003-2006. Aliment Pharmacol Ther. 2011 Oct;34(7):72434.

20 van der Woude CJ, Ardizzone S, Bengtson $\mathrm{MB}$, Fiorino G, Fraser G, Katsanos K, et al.; European Crohn's and Colitis Organization. The second European evidenced-based consensus on reproduction and pregnancy in inflammatory bowel disease. J Crohn's Colitis. 2015 Feb;9(2):107-24.

21 Livingston G, Cohn D. Childlessness up among all women; down among women with advanced degrees. Washington (DC): Pew Research Center; 2010.

22 Mountifield R, Bampton P, Prosser R, Muller $\mathrm{K}$, Andrews JM. Fear and fertility in inflammatory bowel disease: a mismatch of perception and reality affects family planning decisions. Inflamm Bowel Dis. 2009 May;15(5): 720-5.

23 Tavernier N, Fumery M, Peyrin-Biroulet L, Colombel JF, Gower-Rousseau C. Systematic review: fertility in non-surgically treated inflammatory bowel disease. Aliment Pharmacol Ther. 2013 Oct;38(8):847-53.

24 Nguyen GC, Seow CH, Maxwell C, Huang V, Leung Y, Jones J, et al. The Toronto Consensus Statements for the Management of Inflammatory Bowel Disease in Pregnancy. Gastroenterology. 2016;150(3):734-57.e1.

25 Heetun ZS, Byrnes C, Neary P, O’Morain C. Review article: reproduction in the patient with inflammatory bowel disease. Aliment Pharmacol Ther. 2007 Aug;26(4):513-33.

26 Palomba S, Sereni G, Falbo A, Beltrami M, Lombardini S, Boni MC, et al. Inflammatory bowel diseases and human reproduction: a comprehensive evidence-based review. World J Gastroenterol. 2014 Jun;20(23): 7123-36.

27 Mahadevan U, McConnell RA, Chambers CD. Drug Safety and Risk of Adverse Outcomes for Pregnant Patients With Inflammatory Bowel Disease. Gastroenterology. 2017; 152(2):451-62.e2.

28 Ban L, Tata LJ, Humes DJ, Fiaschi L, Card T. Decreased fertility rates in 9639 women diagnosed with inflammatory bowel disease: a United Kingdom population-based cohort study. Aliment Pharmacol Ther. 2015 Oct; 42(7):855-66.

29 de Lima A, Zelinkova Z, Mulders AG, van der Woude CJ. Preconception Care Reduces Relapse of Inflammatory Bowel Disease During Pregnancy. Clin Gastroenterol Hepatol. 2016; 14(9):1285-92.e1.

30 McConnell RA, Mahadevan U. Pregnancy and the Patient with Inflammatory Bowel Disease: Fertility, Treatment, Delivery, and Complications. Gastroenterol Clin North Am. 2016 Jun;45(2):285-301.

31 Cornish JA, Tan E, Teare J, Teoh TG, Rai R, Darzi AW, et al. The effect of restorative proctocolectomy on sexual function, urinary function, fertility, pregnancy and delivery: a systematic review. Dis Colon Rectum. 2007 Aug; 50(8):1128-38.

32 Rajaratnam SG, Eglinton TW, Hider P, Fearnhead NS. Impact of ileal pouch-anal anastomosis on female fertility: meta-analysis and systematic review. Int J Colorectal Dis. 2011 Nov;26(11):1365-74.

33 Waljee A, Waljee J, Morris AM, Higgins PD. Threefold increased risk of infertility: a metaanalysis of infertility after ileal pouch anal anastomosis in ulcerative colitis. Gut. 2006 Nov;55(11):1575-80.

34 Bartels SA, D’Hoore A, Cuesta MA, Bensdorp AJ, Lucas C, Bemelman WA. Significantly increased pregnancy rates after laparoscopic restorative proctocolectomy: a cross-sectional study. Ann Surg. 2012 Dec;256(6):1045-8.

35 Beyer-Berjot L, Maggiori L, Birnbaum D, Lefevre JH, Berdah S, Panis Y. A total laparoscopic approach reduces the infertility rate after ileal pouch-anal anastomosis: a 2-center study. Ann Surg. 2013 Aug;258(2):275-82.

36 Practice Committee of American Society for Reproductive Medicine. Diagnostic evaluation of the infertile female: a committee opinion. Fertil Steril. 2012 Aug;98(2):302-7.

37 Pabby V, Oza SS, Dodge LE, Hacker MR, Moragianni VA, Correia K, et al. In Vitro Fertilization Is Successful in Women With Ulcerative Colitis and Ileal Pouch Anal Anastomosis. Am J Gastroenterol. 2015 Jun;110(6):7927. 
38 Ananthakrishnan AN, Martin C, Kane S, Sandler RS, Long MD. Paternal Disease Activity Is Associated With Difficulty in Conception Among Men With Inflammatory Bowel Diseases. Clin Gastroenterol Hepatol. 2019 Jan;17(1):203-4.

39 Birnie GG, McLeod TI, Watkinson G. Incidence of sulphasalazine-induced male infertility. Gut. 1981 Jun;22(6):452-5.

40 Narendranathan M, Sandler RS, Suchindran $\mathrm{CM}$, Savitz DA. Male infertility in inflammatory bowel disease. J Clin Gastroenterol. 1989 Aug;11(4):403-6.

41 Sussman A, Leonard JM. Psoriasis, methotrexate, and oligospermia. Arch Dermatol. 1980 Feb;116(2):215-7.

42 Mahadevan U, Matro R. Care of the Pregnant Patient With Inflammatory Bowel Disease. Obstet Gynecol. 2015 Aug;126(2):401-12.

43 Paschou S, Voulgari PV, Vrabie IG, Saougou IG, Drosos AA. Fertility and reproduction in male patients with ankylosing spondylitis treated with infliximab. J Rheumatol. 2009 Feb;36(2):351-4.

44 Puchner R, Danninger K, Puchner A, Pieringer H. Impact of TNF-blocking agents on male sperm characteristics and pregnancy outcomes in fathers exposed to TNF-blocking agents at time of conception. Clin Exp Rheumatol. 2012 Sep-Oct;30(5):765-7.

45 Sands K, Jansen R, Zaslau S, Greenwald D. Review article: the safety of therapeutic drugs in male inflammatory bowel disease patients wishing to conceive. Aliment Pharmacol Ther. 2015 May;41(9):821-34.

46 Akbari M, Shah S, Velayos FS, Mahadevan U, Cheifetz AS. Systematic review and metaanalysis on the effects of thiopurines on birth outcomes from female and male patients with inflammatory bowel disease. Inflamm Bowel Dis. 2013 Jan;19(1):15-22.

47 Johnson E, Carlsen E, Nazir M, Nygaard K. Morbidity and functional outcome after restorative proctocolectomy for ulcerative colitis. Eur J Surg. 2001 Jan;167(1):40-5.

48 Davies RJ, O'Connor BI, Victor C, MacRae HM, Cohen Z, McLeod RS. A prospective evaluation of sexual function and quality of life after ileal pouch-anal anastomosis. Dis Colon Rectum. 2008 Jul;51(7):1032-5.

49 Korelitz BI. Inflammatory bowel disease and pregnancy. Gastroenterol Clin North Am. 1998 Mar;27(1):213-24.

50 Bortoli A, Saibeni S, Tatarella M, Prada A, Beretta L, Rivolta R, et al.; Study Group for Inflammatory Bowel Diseases GSMII. Pregnancy before and after the diagnosis of inflammatory bowel diseases: retrospective case-control study. J Gastroenterol Hepatol. 2007 Apr; 22(4):542-9.

51 Schulze H, Esters P, Dignass A. Review article: the management of Crohn's disease and ulcerative colitis during pregnancy and lactation. Aliment Pharmacol Ther. 2014 Nov; 40(9):991-1008.

52 Riis L, Vind I, Politi P, Wolters F, Vermeire S, Tsianos E, et al.; European Collaborative study group on Inflammatory Bowel Disease. Does pregnancy change the disease course? A study in a European cohort of patients with inflammatory bowel disease. Am J Gastroenterol. 2006 Jul;101(7):1539-45.

53 Castiglione F, Pignata S, Morace F, Sarubbi A, Baratta MA, D'Agostino L, et al. Effect of pregnancy on the clinical course of a cohort of women with inflammatory bowel disease. Ital J Gastroenterol. 1996 May;28(4):199-204.

54 Selinger CP, Leong RW, Lal S. Pregnancy related issues in inflammatory bowel disease: evidence base and patients' perspective. World J Gastroenterol. 2012 Jun;18(21): 2600-8.

55 Bengtson MB, Aamodt G, Mahadevan U, Vatn MH. Inadequate Gestational Weight Gain, the Hidden Link Between Maternal IBD and Adverse Pregnancy Outcomes: Results from the Norwegian Mother and Child Cohort Study. Inflamm Bowel Dis. 2017 Jul; 23(7):1225-33.

56 Abdul Sultan A, West J, Ban L, Humes D, Tata LJ, Fleming KM, et al. Adverse Pregnancy Outcomes Among Women with Inflammatory Bowel Disease: A Population-Based Study from England. Inflamm Bowel Dis. 2016 Jul;22(7):1621-30.

57 Kammerlander H, Nielsen J, Kjeldsen J, Knudsen T, Friedman S, Nørgård B. The Effect of Disease Activity on Birth Outcomes in a Nationwide Cohort of Women with Moderate to Severe Inflammatory Bowel Disease. Inflamm Bowel Dis. 2017 Jun;23(6):1011-8.

58 Costa F, Mumolo MG, Ceccarelli L, Bellini M, Romano MR, Sterpi C, et al. Calprotectin is a stronger predictive marker of relapse in ulcerative colitis than in Crohn's disease. Gut. 2005 Mar;54(3):364-8.

59 Carroccio A, Iacono G, Cottone M, Di Prima L, Cartabellotta F, Cavataio F, et al. Diagnostic accuracy of fecal calprotectin assay in distinguishing organic causes of chronic diarrhea from irritable bowel syndrome: a prospective study in adults and children. Clin Chem. 2003 Jun;49(6 Pt 1):861-7.

60 Bressler B, Marshall JK, Bernstein CN, Bitton A, Jones J, Leontiadis GI, et al. Clinical practice guidelines for the medical management of nonhospitalized ulcerative colitis: the Toronto consensus. Gastroenterology. 2015;148(5): 1035-58.e3.

61 Kammerlander H, Nielsen J, Kjeldsen J, Knudsen T, Gradel KO, Friedman S, et al. Fecal Calprotectin During Pregnancy in Women With Moderate-Severe Inflammatory Bowel Disease. Inflamm Bowel Dis. 2018 Mar; 24(4):839-48.

62 Jharap B, de Boer NK, Stokkers P, Hommes DW, Oldenburg B, Dijkstra G, et al.; Dutch Initiative on Crohn and Colitis. Intrauterine exposure and pharmacology of conventional thiopurine therapy in pregnant patients with inflammatory bowel disease. Gut. 2014 Mar; 63(3):451-7.

63 Seow $\mathrm{CH}$, Leung $\mathrm{Y}$, Vande Casteele $\mathrm{N}$, Ehteshami Afshar E, Tanyingoh D, Bindra G, et al. The effects of pregnancy on the pharmacokinetics of infliximab and adalimumab in inflammatory bowel disease. Aliment Pharmacol Ther. 2017 May;45(10):1329-38.

64 Kanis SL, de Lima-Karagiannis A, van der Ent C, Rizopoulos D, van der Woude CJ. AntiTNF Levels in Cord Blood at Birth are Associated with Anti-TNF Type. J Crohn's Colitis. 2018 Jul;12(8):939-47.

65 Flanagan E, Gibson P, Ross A, Rosella O, Bell SJ. Stability of serum concentrations of infliximab and adalimumab across pregnancy in IBD. J Crohn's Colitis. 2019;13 Supplement_1:S449-50.

66 Julsgaard M, Nørgaard M, Hvas CL, Buck D, Christensen LA. Self-reported adherence to medical treatment prior to and during pregnancy among women with ulcerative colitis. Inflamm Bowel Dis. 2011 Jul;17(7): 1573-80.

67 Nielsen MJ, Nørgaard M, Holland-Fisher P, Christensen LA. Self-reported antenatal adherence to medical treatment among pregnant women with Crohn's disease. Aliment Pharmacol Ther. 2010 Jul;32(1):49-58.

68 Bar-Oz B, Moretti ME, Boskovic R, O’Brien L, Koren $\mathrm{G}$. The safety of quinolones-a metaanalysis of pregnancy outcomes. Eur J Obstet Gynecol Reprod Biol. 2009 Apr;143(2):75-8.

69 Sheehy O, Santos F, Ferreira E, Berard A. The use of metronidazole during pregnancy: a review of evidence. Curr Drug Saf. 2015;10(2): 170-9.

70 Czeizel AE, Rockenbauer M, Sørensen HT, Olsen J. Augmentin treatment during pregnancy and the prevalence of congenital abnormalities: a population-based case-control teratologic study. Eur J Obstet Gynecol Reprod Biol. 2001 Aug;97(2):188-92.

71 Reid G, Kumar H, Khan AI, Rautava S, Tobin J, Salminen S. The case in favour of probiotics before, during and after pregnancy: insights from the first 1,500 days. Benef Microbes. 2016 Jun;7(3):353-62.

72 Cury DB, Moss AC. Treatment of Crohn's disease in pregnant women: drug and multidisciplinary approaches. World J Gastroenterol. 2014 Jul;20(27):8790-5.

73 Nørgård B, Fonager K, Pedersen L, Jacobsen BA, Sørensen HT. Birth outcome in women exposed to 5-aminosalicylic acid during pregnancy: a Danish cohort study. Gut. 2003 Feb; 52(2):243-7.

74 Nielsen OH, Maxwell C, Hendel J. IBD medications during pregnancy and lactation. Nat Rev Gastroenterol Hepatol. 2014 Feb;11(2): 116-27.

75 Gallinger ZR, Nguyen GC. Presence of phthalates in gastrointestinal medications: is there a hidden danger? World J Gastroenterol. 2013 Nov; 19(41):7042-7.

76 Park-Wyllie L, Mazzotta P, Pastuszak A, Moretti ME, Beique L, Hunnisett L, et al. Birth defects after maternal exposure to corticosteroids: prospective cohort study and metaanalysis of epidemiological studies. Teratology. 2000 Dec;62(6):385-92. 
77 Hviid A, Mølgaard-Nielsen D. Corticosteroid use during pregnancy and risk of orofacial clefts. CMAJ. 2011 Apr;183(7):796-804.

78 Lin K, Martin C, Dassopoulos T, Esposti SD, Wolf DC, Esposti SD, et al. Pregnancy outcomes amongst mothers with inflammatory bowel disease exposed to systemic corticosteroids: results of the PIANO registry [abstract]. Gastroenterology. 2014;146(5):146.

79 Beaulieu DB, Ananthakrishnan AN, Issa M, Rosenbaum L, Skaros S, Newcomer JR, et al. Budesonide induction and maintenance therapy for Crohn's disease during pregnancy. Inflamm Bowel Dis. 2009 Jan;15(1):25-8.

80 Martínez Lopez JA, Loza E, Carmona L. Systematic review on the safety of methotrexate in rheumatoid arthritis regarding the reproductive system (fertility, pregnancy, and breastfeeding). Clin Exp Rheumatol. 2009 JulAug;27(4):678-84.

81 Weber-Schoendorfer C, Chambers C, Wacker E, Beghin D, Bernard N, Shechtman S, et al.; Network of French Pharmacovigilance Centers. Pregnancy outcome after methotrexate treatment for rheumatic disease prior to or during early pregnancy: a prospective multicenter cohort study. Arthritis Rheumatol. 2014 May;66(5):1101-10.

82 Polifka JE, Friedman JM. Teratogen update: azathioprine and 6-mercaptopurine. Teratology. 2002 May;65(5):240-61.

83 Langagergaard V, Pedersen L, Gislum M, Nørgard B, Sørensen HT. Birth outcome in women treated with azathioprine or mercaptopurine during pregnancy: A Danish nationwide cohort study. Aliment Pharmacol Ther. 2007 Jan;25(1):73-81.

84 Coelho J, Beaugerie L, Colombel JF, Hébuterne $\mathrm{X}$, Lerebours $\mathrm{E}$, Lémann $\mathrm{M}$, et al.; CESAME Pregnancy Study Group (France). Pregnancy outcome in patients with inflammatory bowel disease treated with thiopurines: cohort from the CESAME Study. Gut. 2011 Feb;60(2):198-203.

85 Shim L, Eslick GD, Simring AA, Murray H, Weltman MD. The effects of azathioprine on birth outcomes in women with inflammatory bowel disease (IBD). J Crohn's Colitis. 2011 Jun;5(3):234-8.

86 Casanova MJ, Chaparro $M$, Domènech $\mathrm{E}$, Barreiro-de Acosta M, Bermejo F, Iglesias E, et al. Safety of thiopurines and anti-TNF- $\alpha$ drugs during pregnancy in patients with inflammatory bowel disease. Am J Gastroenterol. 2013 Mar;108(3):433-40.

87 Francella A, Dyan A, Bodian C, Rubin P, Chapman M, Present DH. The safety of 6-mercaptopurine for childbearing patients with inflammatory bowel disease: a retrospective cohort study. Gastroenterology. 2003 Jan; 124(1):9-17.

88 Mahadevan U, Martin C, Sandler R, Kane SV, Dubinsky M, Lewis JD, et al. PIANO: a 1000 patient prospective registry of pregnancy outcomes in women with IBD exposed to immunomodulators and biologic therapy [abstract]. Gastroenterology. 2012;142(5):142.
89 Chaparro M, Verreth A, Lobaton T, Gravito-Soares E, Julsgaard M, Savarino E, et al. Long-Term Safety of In Utero Exposure to Anti-TNFa Drugs for the Treatment of Inflammatory Bowel Disease: Results from the Multicenter European TEDDY Study. Am J Gastroenterol. 2018 Mar;113(3):396403.

90 Dignass A, Lindsay JO, Sturm A, Windsor A, Colombel JF, Allez M, et al. Second European evidence-based consensus on the diagnosis and management of ulcerative colitis part 2: current management. J Crohn's Colitis. 2012 Dec;6(10):991-1030.

91 Mahadevan U, Dubinsky MC, Su C, Lawendy N, Jones TV, Marren A, et al. Outcomes of Pregnancies With Maternal/Paternal Exposure in the Tofacitinib Safety Databases for Ulcerative Colitis. Inflamm Bowel Dis. 2018 Nov;24(12):2494-500.

92 Simister NE. Placental transport of immunoglobulin G. Vaccine. 2003 Jul;21(24): 3365-9.

93 Kane SV, Acquah LA. Placental transport of immunoglobulins: a clinical review for gastroenterologists who prescribe therapeutic monoclonal antibodies to women during conception and pregnancy. Am J Gastroenterol. 2009 Jan;104(1):228-33.

94 Nielsen OH, Loftus EV Jr, Jess T. Safety of TNF- $\alpha$ inhibitors during IBD pregnancy: a systematic review. BMC Med. 2013 Jul; 11(1):174.

95 Gisbert JP, Chaparro M. Safety of anti-TNF agents during pregnancy and breastfeeding in women with inflammatory bowel disease. Am J Gastroenterol. 2013 Sep;108(9):142638.

96 Arsenescu R, Arsenescu V, de Villiers WJ. TNF- $\alpha$ and the development of the neonatal immune system: implications for inhibitor use in pregnancy. Am J Gastroenterol. 2011 Apr;106(4):559-62.

97 Lichtenstein GR, Feagan BG, Cohen RD, Salzberg BA, Diamond RH, Price S, et al. Serious infection and mortality in patients with Crohn's disease: more than 5 years of follow-up in the TREAT ${ }^{\mathrm{TM}}$ registry. Am J Gastroenterol. 2012 Sep;107(9):1409-22.

98 Jürgens $M$, Brand $S$, Filik L, Hübener C, Hasbargen U, Beigel F, et al. Safety of adalimumab in Crohn's disease during pregnancy: case report and review of the literature. Inflamm Bowel Dis. 2010 Oct;16(10):16346.

99 Mahadevan U, Vermeire S, Wolf D, Förger F, Cush JJ, Golembesky A, et al. Pregnancy outcomes after exposure to certolizumab pegol: updated results from safety surveillance [abstract]. Gastroenterology. 2015; 148(4): 148 .

100 Narula N, Al-Dabbagh R, Dhillon A, Sands BE, Marshall JK. Anti-TNFa therapies are safe during pregnancy in women with inflammatory bowel disease: a systematic review and meta-analysis. Inflamm Bowel Dis. 2014 Oct;20(10):1862-9.
101 Takeda Pharmaceuticals America Inc. ENTYVIO $^{\circledR}$ (vedolizumab). Prescribing Information; 2014.

102 Mahadevan U, Vermeire S, Lasch K, Abhyankar B, Bhayat F, Blake A, et al. Vedolizumab exposure in pregnancy: outcomes from clinical studies in inflammatory bowel disease. Aliment Pharmacol Ther. 2017 Apr 45(7):941-50.

103 Dubinsky M, Mahadevan U, Vermeire S. Vedolizumab exposure in pregnancy: outcomes from clinical studies in inflammatory bowel disease [abstract]. J Crohn's Colitis. 2015;9.

104 Moens A, van Hoeve K, Humblet E. Outcome of pregnancies in female IBD patients treated with vedolizumab. ECCO congress oral presentation. 2019

105 Schaufelberg B, Horn E, Cather J. Pregnancy outcomes in women exposed to ustekinum$\mathrm{ab}$ in the psoriasis clinical development program [abstract]. J Am Acad Dermatol. 2014; 70(Supplement 1):AB178.

106 Mahadevan U, Dotan I. 2018. Available from: https://e-learning.ecco-ibd.eu/mod/ page/view.php?id=581.

107 Torres J, Boyapati RK, Kennedy NA, Louis E, Colombel JF, Satsangi J. Systematic Review of Effects of Withdrawal of Immunomodulators or Biologic Agents From Patients With Inflammatory Bowel Disease. Gastroenterology. 2015 Dec;149(7):171630.

108 Reinisch W, Sandborn WJ, Rutgeerts P, Feagan BG, Rachmilewitz D, Hanauer SB, et al. Long-term infliximab maintenance therapy for ulcerative colitis: the ACT- 1 and -2 extension studies. Inflamm Bowel Dis. 2012 Feb;18(2):201-11.

109 Vande Casteele N, Gils A, Singh S, Ohrmund L, Hauenstein S, Rutgeerts $P$, et al. Antibody response to infliximab and its impact on pharmacokinetics can be transient. Am J Gastroenterol. 2013 Jun;108(6):96271.

110 Nguyen GC, Boudreau H, Harris ML, Maxwell CV. Outcomes of obstetric hospitalizations among women with inflammatory bowel disease in the United States. Clin Gastroenterol Hepatol. 2009 Mar;7(3):32934.

111 Brandt LJ, Estabrook SG, Reinus JF. Results of a survey to evaluate whether vaginal delivery and episiotomy lead to perineal involvement in women with Crohn's disease. Am J Gastroenterol. 1995 Nov;90(11):191822.

112 Kane S, Lemieux N. The role of breastfeeding in postpartum disease activity in women with inflammatory bowel disease. Am J Gastroenterol. 2005 Jan;100(1):102-5.

113 Seirafi M, de Vroey B, Amiot A, Seksik P, Roblin X, Allez M, et al. Factors associated with pregnancy outcome in anti-TNF treated women with inflammatory bowel disease. $\mathrm{Al}$ iment Pharmacol Ther. 2014 Aug;40(4):36373. 
114 Mahadevan U, Robinson C, Bernasko N, Boland B, Chambers C, Dubinsky M, et al. Inflammatory Bowel Disease in Pregnancy Clinical Care Pathway: A Report From the American Gastroenterological Association IBD Parenthood Project Working Group. Inflamm Bowel Dis. 2019 Mar;25(4):62741.

115 Huang H, Wang H, He M. Early oral feeding compared with delayed oral feeding after cesarean section: a meta-analysis. J Matern Fetal Neonatal Med. 2016;29(3):423-9.

116 Whiteley I, Gullick J. The embodied experience of pregnancy with an ileostomy. J Clin Nurs. 2018 Nov;27(21-22):3931-44.

117 Meyers D. Breastfeeding and health outcomes. Breastfeed Med. 2009 Oct;4(Suppl 1):S13-5.

118 Matro R, Martin C, Wolf D, Shah SA, Mahadevan U. Detection of biologic agents in breast milk and implication for infection, growth and development in infants born to women with inflammatory bowel disease: results from the PIANO registry [abstract]. Gastroenterology. 2015;148(4):148.

119 Cleary BJ, Källén B. Early pregnancy azathioprine use and pregnancy outcomes. Birth Defects Res A Clin Mol Teratol. 2009 Jul; 85(7):647-54

120 Matro R, Martin CF, Wolf D, Shah SA, Mahadevan U. Exposure Concentrations of Infants Breastfed by Women Receiving Biologic Therapies for Inflammatory Bowel Diseases and Effects of Breastfeeding on Infections and Development. Gastroenterology. 2018 Sep;155(3):696-704.

121 Julsgaard M, Kjeldsen J, Bibby BM, Brock B, Baumgart DC. Vedolizumab Concentrations in the Breast Milk of Nursing Mothers With Inflammatory Bowel Disease. Gastroenterology. 2018;154(3):752-4.e1.

122 Lahat A, Shitrit AB, Naftali T, Milgrom Y, Elyakim R, Goldin E, et al. Vedolizumab Levels in Breast Milk of Nursing Mothers With Inflammatory Bowel Disease. J Crohn's Colitis. 2018 Jan;12(1):120-3.
123 Molnár T, Farkas K, Nagy F, Lakatos PL, Miheller P, Nyári T, et al. Pregnancy outcome in patients with inflammatory bowel disease according to the activity of the disease and the medical treatment: a case-control study. Scand J Gastroenterol. 2010 Nov;45(11): 1302-6.

124 Santos MP, Gomes C, Torres J. Familial and ethnic risk in inflammatory bowel disease. Ann Gastroenterol. 2018 Jan-Feb;31(1):1423.

125 Moller FT, Andersen V, Wohlfahrt J, Jess T. Familial risk of inflammatory bowel disease: a population-based cohort study 1977-2011. Am J Gastroenterol. 2015 Apr;110(4):56471.

126 Mahadevan U, Martin C, Chambers C, Kane SV, Dubinsky M, Sandborn W, et al. Achievement of developmental milestones among offspring of women with inflammatory bowel disease: the PIANO registry [abstract]. Gastroenterology. 2014;146(5): 146. 